\title{
POLYCYTHEMIA INDUCED BY TINCTURE OF CANTHARIDES
}

\author{
PRELIMINARY REPCRT * \\ SAMUEL T. LIPSITZ, M.D. \\ A. L. FUERTH, M.D., AND A. J. CROSS, M.D. \\ ST. LOUIS
}

In a case of tincture of cantharides poisoning which recently came under our observation, ${ }^{1}$ a pronounced polycythemia was discovered. Inasmuch as this is a hitherto undescribed phenomenon following the introduction of cantharides into the body, and in order to eliminate any possible error in technic, we determined to study experimentally the effect of cantharides on the blood. Though there are some substances said to produce an increase in the number of red corpuscles, it is questionable whether any of them has been proved to produce an absolute and lasting polycythemia.

Lamson, ${ }^{2}$ experimenting with epinephrin, was able to produce a rapid increase in the number of red corpuscles, but concluded that this was due to its specific action on the liver, causing a diminution in its size and a constriction of the hepatic capillaries. He, however, believes that when epinephrin is injected into the portal vein contraction of the liver capillaries takes place, and erythrocytes lying dormant in these vessels are thrown into the general circulation, which, with a synchronous reduction or concentration of the blood plasma, causes an increase in the number of erythrocytes per unit volume of blood. He concludes that the liver acts as a reservoir for erythrocytes. He has demonstrated that epinephrin, intravenously injected into a dog or cat causes an increase in the number of erythrocytes of $1,500,000$ to $2,000,000$ per c.mm. of blood in from five to ten minutes, lasting about one half hour and then gradually returning to normal. It may be deduced from his results that the effect of epinephrin in producing an increase of erythrocytes in the blood is mechanical and transitory, really limiting itself to a redistribution of the mature blood elements and manifesting itself as a relative peripheral polycythemia with

*Submitted for publication Aug. 4, 1917.

* From the Service of the Department of Internal Medicine of the St. Louis University, School of Medicine.

1. Lipsitz, S. T., and Cross, A. J.: A Case of Cantharides Poisoning with Special Reference to the Blood Picture. This issue, p. 889.

2. Lamson, P. D.: The Processes Taking Place in the Body by Which the Number of Erythrocytes Per Unit Volume of the Blood Is Increased. Proc. Nat. Acad. Sc., 1916, 2, 365. 
transitory visceral anemia. It does not act through its effect on the blood-forming organs. Lamson was not able to obtain these results in similar experiments on rabbits.

It has been found that asphyxia in any form, such as is produced by carbon monoxid gas, pulmonary obstruction, passive congestion due to heart lesions, etc., causes the number of red blood cells to increase. Variations in atmospheric pressure and in the oxygen content of the blood act likewise. Lamson ${ }^{3}$ has shown that emotional stress, excitement and fright may produce transitory polycythemia. Nicotin is also said to have this effect on the blood. This is, most likely, due to its depressing action on the respiratory centers, causing partial asphyxia. Thus far, cantharides is not known to have this influence on the vasomotor mechanism, the capillaries or the liver.

Gruner ${ }^{4}$ states that a transitory polycythemia may rapidly appear after the incidence of hemolysis. We are not prepared to say in what way cantharides produces an increase in the number of red corpuscles in the blood. Whether it acts by affecting the vascular system of the liver or the vasomotor mechanism, or whether it acts by hemolysis and the secondary elaboration of new cells, or by the stimulation of the reservoirs of red blood cells, or whether it activates primarily the blood-forming organs, we are at present unable to say.

In our experiments we found that cantharides introduced into the stomachs of rabbits produced a definite polycythemia, not as transitory as that of epinephrin, but lasting in some instances as long as eight days. In each of twelve rabbits on which experiments were made, some increase in the number of erythrocytes per cubic millimeter was noted. In these animals as well as in the patient suffering from cantharides poisoning ${ }^{1}$ a relative though in no way constant or char acteristic increase in the number of leukocytes was also present. The hemoglobin percentage often rose and fell synchronously with the erythrocyte count. It is interesting to note that the erythremia became apparent within twenty-four to seventy-two hours after the introduction of the cantharides.

In the following experiments tincture of cantharides was administered to the animals through a soft rubber catheter inserted into the stomach.

Rabbit Experiment 1.-First day (normal erythrocyte count), 6,111,000, followed by tincture of cantharides ( 15 minims).

Second day (erythrocyte count), 8,740,000, followed by tincture of cantharides (30 minims). This quantity was lethal, as the rabbit died twenty-four hours later.

3. Lamson, P. D.: The Rôle of the Liver in Acute Polycythemia. Proc. Nat. Acad. Sc., 1915, 1, 521.

4. Gruner, O. C.: Biology of Blood Cells, Macmillan Co., Toronto, 1913. 
Necropsy Protocol. - The heart appeared normal; the trachea and lungs normal; the esophagus was injected and completely covered with a grayishwhite eschar which could not be wiped off. The stomach showed two injected, irregular ulcers, 1 to $2 \mathrm{~cm}$. in diameter. The liver showed some cloudy swelling. The kidneys were slightly enlarged and injected; the bladder was congested; urine cloudy, showing a great many white and red blood corpuscles and a few granular casts. The bone marrow appeared normal.

Rabbit Experiment 2.--Erythrocyte Count

1st day (normal) ..... 5,560,000

Followed by tincture cantharides (15 minims)

$2 \mathrm{~d}$ day $\ldots \ldots \ldots \ldots \ldots, 9,800,000$

$3 \mathrm{~d}$ day............ 8,840,000

4 th day.......... 7,970,000
5 th day............6, 6,490,000

7 th day ............6,530,000

8 th day............ 7,180,000

9 th day............ 4,910,000

10 th day........... 4,620,000

(See Chart 1)

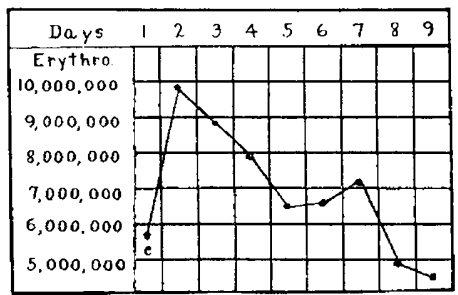

Chart 1.-Blood count and curve in Rabbit Experiment 2. In this and the following charts, $C=$ tincture of cantharides.

Rabbit Experiment 3.-Erythrocyte Count

1st day (normal) ..... 6,550,000

Followed by tincture cantharides (15 minims)

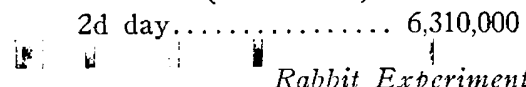
Rabbit Experiment 4.-Erythrocyte Count

1st day (normal) ..... 5,850,000

Followed by tincture cantharides (15 minims)

2 d day........... 8,120,000

3d day............ $7,560,000$

4 th day........... $6,450,000$

5 th day........... $6,210,000$

6 th day.............6,620,000

7 th day........... $6,250,000$

8 th day...........6, 6,310,000

Followed by tincture cantharides (15 minims)

9th day........... 6,620,000

10 th day............ 7,230,000

11 th day........... $6,950,000$

12 th day............ $6,730,000$
$3 d$ day

$8,670,000$

6 th day............11,260,000

7th day, rabbit developed a skin infection and had to be killed

13th day............ $6,250,000$

14 th day. . . . . . . . . . 6, 640,000

15 th day. . . . . . . . $6,980,000$

16 th day $\ldots \ldots \ldots \ldots \ldots, 5,360,000$

17 th day........... $6,000,000$

Followed by tincture cantharides (20 minims)

18 th day $\ldots \ldots \ldots \ldots \ldots, 7,140,000$

19th day............ $7,050,000$

20 th day ............ $7,260,000$

21 st day............ $7,000,000$

$22 \mathrm{~d}$ day............ $6,600,000$

23 d day. . . . . . . . $6,720,000$

24 th day ........... $6,990,000$

25 th day........... 5,620,000

26th day............ 5,700,000

Experiment 4 shows a very consistent response to the administration of cantharides (see Chart 2). 


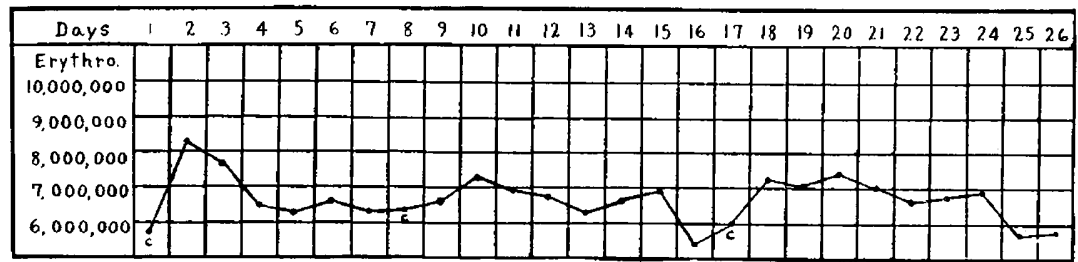

Chart 2.-Blood count and curve in Rabbit Experiment 4.

Rabbit Experiment 5.-Erythrocyte Count

1st day (normal) ..... 5,660,000

Followed by tincture cantharides (20 minims)

2d day............ 6,980,000

$3 \mathrm{~d}$ day................ $6,560,000$

4 th day............ 7,210,000

5 th day............... 8.050,000

6 th day............ 6,980,000

7 th day................ $5,720,000$

8 th day $\ldots \ldots \ldots \ldots \ldots, 5,830,000$

9 th day............... $5,725,000$

Followed by tincture cantharides (20 minims)
10 th day............ 5,890,000

11 th day........... $6,500,000$

12 th day........... $7,130,000$

13 th day........... $7,440,000$

14 th day............ 5,480,000

15 th day............. 5,700,000

16 th day........... $7,540,000$

17 th day........... $7,310,000$

18th day........... 7,090,000

(Chart 3)

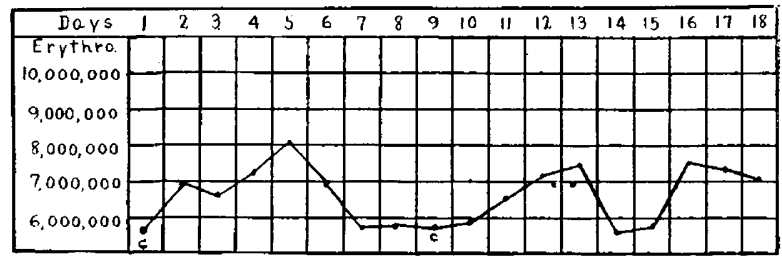

Chart 3.--Blood count and curve in Rabbit Experiment 5.

\section{Rabbit Experiment 6.-Erythrocyte Count}

Ist day (normal) ..... $5.580,000$

2d day (normal) ..... 5.720,000

Followed by tincture cantharides (20 minims)

$3 d$ day $\ldots \ldots \ldots \ldots \ldots, 600,000$

4th dav ........... $6,940,000$

5 th day............... $6.875,000$

6 th day........... 5,010,000

7 th day........... $7.170,000$

8 th day.............. $5,650,000$

9th day ............ 5,500,000

10 th day............ 5.552,000

19 th day
11 th day............ 5,810,000

Followed by tincture cantharides (20 minims)

12th dav ............ $6,120,000$

13 th day............ $6,400,000$

14 th day . . . . . . . . . $6,080,000$

15 th day............... 5,650,000

16 th day. .......... 5,290,000

Followed by tincture cantharides (20 minims)

17 th day............ $6,010,000$

18 th day............... $7,000,000$ $6,800,000$

Rabbit Experiment 7.-Erythrocyte Count

1st day (normal) ..... 6,100,000

2d day (normal) ..... 6.320.000

Followed by tincture cantharides (20 minims)

$3 \mathrm{~d}$ day $\ldots \ldots \ldots \ldots, 8,010,000$ 4th day........... 8,620,000

5 th day............ 9,440,000

6 th day............. $7,530,000$

7 th day............6, $6,700,000$

8 th day........... $6,370,000$ 
Experiment 7 showed a striking rise after the cantharides administration (see Chart 4).

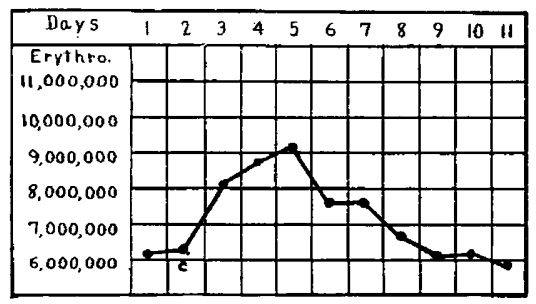

Chart 4.-Blood count and curve in Rabbit Experiment 7.

Rabbit Experincnt 8.-Erythrocyte Count

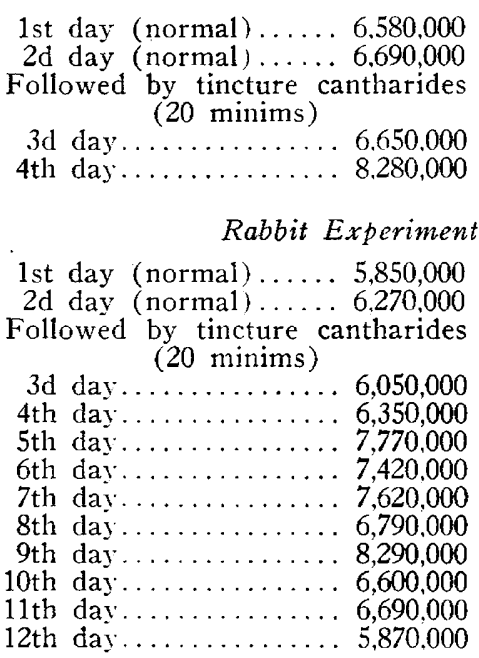

5 th day. . . . . $\ldots \ldots \ldots, 870,000$

6 th day . . . . . . 7,360,000

7 th day . . . . . . 7,160,000

8 th day. . . . . . . . 5,980,000

9 th day . . . . . . . . 6, $6,120,000$

10 th day . . . . . . . 5,910,000

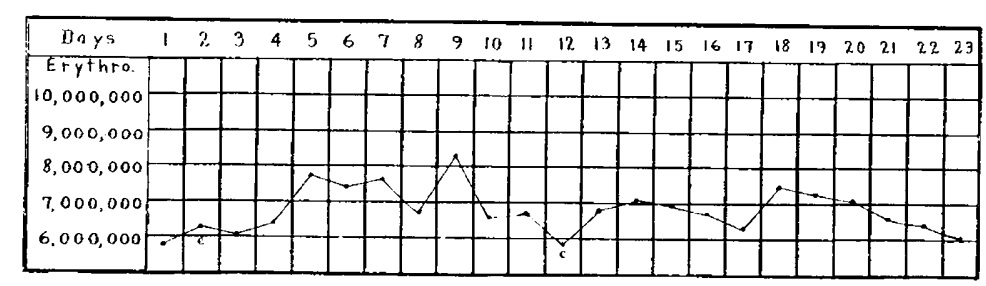

Chart 5.--Blood count and curve in Rabbit Experiment 9.

In Experiment 9 it is shown that the increase in the number of red cells following the administration of cantharides continued for a period of from seven to eight days, which is longer than that usually following the use of other substances known to have this effect. It will also be observed that after the initial rise, a secondary rise occurred in this as well as in some of our other experiments. 
Rabbit Experiment 10.--Erythrocyte Count

1st day (normal) ..... 6,350,000

2 d day (normal) ..... 6,710,000

Followed by tincture cantharides (20 minims)
$3 \mathrm{~d}$ day............ 7,400,000

4th day........... 7,540,000

5th day, rabbit died

Necropsy Findings.-Right upper lobe, lobar pneumonia; acute nephritis; no other striking findings.

Rabbit Experiment 11.-Erythrocyte Count

\begin{tabular}{|c|c|}
\hline & \\
\hline 1st day (normal) ......6, 6,300,000 & 4th day... \\
\hline $2 \mathrm{~d}$ day (normal) ..... $6,880,000$ & 5 th day... \\
\hline $\begin{array}{l}\text { ollowed by tincture cantharides } \\
(15 \text { minims })\end{array}$ & . $7,590,000$ \\
\hline 3d day $\ldots \ldots \ldots \ldots \ldots, 7,980,000$ & $\begin{array}{r}5,640,000 \\
5,720,000\end{array}$ \\
\hline Rabbit Experiment & Erythrocyte Count \\
\hline 1st day (normal) $\ldots \ldots, 6,400,000$ & 4th day...... \\
\hline $2 \mathrm{~d}$ day (normal) $\ldots \ldots, 5,850,000$ & 5th day. \\
\hline Followed by tincture cantharides & $6,520,000$ \\
\hline $3 \mathrm{~d}$ day $\ldots \ldots \ldots \ldots \ldots, 7,820,000$ & 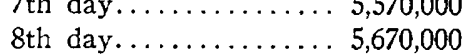 \\
\hline
\end{tabular}

A definite polycythemia can be experimentally produced by cantharides.

This polycythemia may be brought about with a single dose and may continue as long as eight days, when administered as in the above experiments.

It is probable that in some manner - possibly by hemolysis - it stimulates the blood-forming organs or brings about a concentration of the blood, for unlike epinephrin with its transitory action on the liver capillaries, it is slow to produce a rise in the number of red cells and slow to relinquish its effect. 